\title{
Silent neuropathy in leprosy: an epidemiological description
}

\author{
W. H. VAN BRAKEL* \& I. B. KHAWAS \\ Green Pastures Hospital, P.O. Box 28, Pokhara, Nepal
}

\section{Accepted for publication 26 April 1994}

Summary This paper presents epidemiological data on silent nerve function
impairment in leprosy based on a retrospective study of 536 patients registered at
Green Pastures Hospital, Pokhara, West Nepal. Because of the multiple possible
aetiologies it is proposed that the clinical phenomenon should be named 'Silent
Neuropathy' (SN). We defined this as sensory or motor impairment without skin
signs of reversal reaction or erythema nodosum leprosum (ENL), without
evident nerve tenderness and without spontaneous complaints of nerve pain
(burning or shooting pain), paraesthesia or numbness. The functioning of the
main peripheral nerve trunks known to be affected in leprosy was assessed using
a nylon filament to test touch thresholds and a manual voluntary muscle test to
quantify muscle strength.

Almost $7 \%$ of new patients had SN at first examination. The incidence rate of SN among the 336 new patients who were available for follow-up was $4 \cdot 1$ per 100 person years at risk. In total, $75 \%$ of all SN episodes diagnosed after the start of chemotherapy occurred during the first year of treatment. During steroid treatment the sensory and motor function in nerves affected by $\mathrm{SN}$ improved significantly ( $p=0.012$, Wilcoxon matched-pairs signed ranks test) over a period of 3 months. The patients with more extensive clinical disease (3/9 or more body areas involved, more than 3 enlarged nerves or a positive skin smear) were found to be at increased risk of developing $\mathrm{SN}$.

We discuss 4 different possible aetiologies of SN: 1, Schwann cell pathology; 2, nerve fibrosis; 3, cell-mediated immune reaction; and 4, intra-neural ENL. Some epidemiological evidence is presented that suggests that $\mathrm{SN}$ cannot be equated with a 'reversal reaction expressing itself in the nerves'.

It is recommended that all patients should have a nerve function assessment at every visit to the clinic at least during their first year of treatment. Regular nerve function assessment is essential to detect $\mathrm{SN}$ at an early stage and to prevent permanent impairment of nerve function.

\section{Introduction}

Impairment of sensory or motor nerve function, without symptoms of neuritis has been described as a common phenomenon by a number of authors. ${ }^{1-4}$ Various terms have

* Correspondence: c/o INF, PO Box 5, Pokhara, Nepal. 
been used to describe this phenomenon, including 'quiet nerve paralysis',' 'silent neuritis', ${ }^{2,3}$ and 'nerve reaction." However, we were unable to find any publication on the epidemiology of this phenomenon in a population of nonselected patients. There is no consensus about its aetiology and in many leprosy clinics where no routine nerve function assessments are carried out, it is missed altogether. ${ }^{3,6}$ Assessment of nerve function refers to testing of sensory and motor function of structures innervated by the major nerve trunks commonly affected by leprosy (facial, ulnar, median, radial, lateral popliteal and posterior tibial nerves) and their branches.

Because we regularly encountered SN at Green Pastures Hospital (GPH), in a sizeable proportion of patients requiring steroid treatment for neural impairment, we decided to study this phenomenon in more detail. This was done in the context of the retrospective cohort analysis on leprotic reactions and neural impairment which was carried out at our hospital.

GPH is a 100-bed mission hospital in Pokhara, West Nepal, run by the International Nepal Fellowship under its Leprosy Control Project, which is a joint venture with His Majesty's Government/Nepal. GPH is the main leprosy referral hospital for the West of Nepal.

This study addresses the following questions: 1, what is the prevalence at first examination and incidence rate of SN in the patients studied?; 2, can any risk factors be identified that are prognostic for an increased risk of SN?; 3, how well does it respond to steroid treatment?; and 4, what are the possible aetiologies of SN?

\section{Methods}

\section{STUDY DESIGN}

The current study was part of a retrospective (historic) cohort study of all leprosy patients registering at GPH between January 1988 and January 1992. Both previously treated and untreated patients were included, although, for most purposes, their results were analysed separately.

\section{CRITERIA FOR INCLUSION AND EXCLUSION OF PATIENTS}

All new, previously untreated patients who registered for treatment in GPH during the abovementioned period were included in the study. Patients referred to GPH for treatment of reaction/neuropathy were included, but those whose treatment was started elsewhere more than 1 week before arrival at GPH were excluded.

\section{OUTCOME MEASURES}

The number of patients with $\mathrm{SN}$ among all patients in the cohort stratified by classification and time of onset of neural impairment.

Odds ratios pertaining to the following potential risk factors: age, sex, classification of leprosy, extent of disease (numbers of skin lesions, nerves and body areas involved in the disease), bacteriological index, PGL-1 serological results and type of leprosy treatment (multidrug therapy (MDT) vs dapsone monotherapy (DDS)).

Voluntary muscle test (VMT) and touch sensibility test (TST) scores at various times during and after steroid treatment. 
DIAGNOSIS AND CLASSIFICATION OF LEPROSY

Details on diagnosis and classification, which included clinical examination, counting of the number of body areas involved in the disease, skin smears from routine sites and at least 1 active lesion, PGL-1 antibody testing and histopathology for a limited number of patierits, were described in a previous publication. ${ }^{7}$ Briefly, the body area system is based on a count of the number of body areas out of a total of 9 (head, 4 extremities, front and back, both divided in left and right side) that shows primary or secondary signs of leprosy. These may include skin lesions, enlarged nerves, clawing of fingers and ulcers.

DIAGNOSIS OF REACTIONS AND NERVE FUNCTION IMPAIRMENT

REVERSAL REACTION (RR)

The diagnosis 'reversal reaction' was based on the presence of skin signs, but a patient could have some or all of the following clinical signs:

Skin: redness and swelling of (usually already existing) lesions, sometimes tender in the lesions.

Nerves: of ten signs of neuritis with/without swelling, nerve pain, tenderness or nerve function impairment.

General: sometimes oedema of hands, feet or face, occasionally fever.

SILENT NEUROPATHY (SN)

A patient was diagnosed as having $\mathrm{SN}$ if he showed the following clinical signs and symptoms: sensory or motor impairment (see below) without skin signs of reversal reaction, ENL, without nerve tenderness that had been noticed by the patient and without complaints of nerve pain (burning or shooting pain) or paraesthesia that were mentioned by the patient without specifically asking for them.

There are 3 common clinical scenarios. The first is of a patient who presents with skin signs of leprosy without complaining of his nerves, who during nerve function assessment is found to have sensory and/or motor impairment. The second is the patient who presents because of the consequences of impaired sensory or motor nerve function such as weakness, clawing or a painless ulcer of recent onset, but who does not recall reactive skin lesions or nerve pain. The third is that of a patient who is already taking antileprosy treatment, but who is found to have new neural impairment during a routine follow-up sensory or motor assessment. In this study we called SN a 'reaction'; this does not imply any inference concerning the aetiology.

\section{CROSS-OVER REACTIONS}

Some patients develop more than 1 type of reaction during their time of registration. For example, a borderline lepromatous patient who first has an episode of reversal reaction, followed after some time by an episode of ENL. We called this phenomenon 'cross-over reactions'. 
VOLUNTARY MUSCLE TEST (VMT)

The VMT score consisted of the sum of individual scores $(0-5 ; 0=$ paralysed, $5=$ normal strength) for the following muscles: Facial nerve: orbicularis oculi (only) - maximum score: 5; Ulnar nerve: first dorsal interosseus ('index finger out') and abductor digiti minimi ('little finger out') - maximum score: 10; median nerve: abductor pollicis brevis and opponens pollicis ('thumb up')-maximum score: 10; lateral popliteal nerve: extensor hallucis longus and peroneus longus \& brevis ('lateral foot up') - maximum score: 10 .

\section{TOUCH SENSIBILITY TEST (TST)}

Static touch sensibility of the ulnar and median nerves was tested on the palm of the hand, using a nylon monofilament giving a force of approximately $10 \mathrm{gm}$ when pressed until it bent. The result was recorded as felt or not felt for each of the sites mentioned below. If the patient sometimes felt the touch and sometimes not, the result was recorded as partial. When necessary the test was repeated until the examiner was confident about the patients response. Touch sensibility of the posterior tibial nerve was tested in a similar way using a thicker monofilament, giving a force of about $75 \mathrm{gm}$. The size of these filaments was far from ideal (see Discussion below) but they were the only 2 sizes available in Pokhara at the time. During a normative study of touch sensibility thresholds of healthy Nepali subjects in Pokhara, about $99 \%$ were able to feel a $200 \mathrm{mg}$ monofilament on the hand and more than $95 \%$ a $2 \mathrm{gm}$ monofilament on the sole of the foot (Kets et al., in preparation). The TST score consisted of the sum of touch sensibility test scores given for individual sites $(2=$ monofilament felt, $1=$ doubtful, $0=$ monofilament not felt); the number of sites depending on the nerve tested.

Ulnar nerve: 3 points on the pulp of the little finger, over the 5th metacarpophalangeal (MCP) joint and on the hypothemar eminence respectively-maximum score: 6 ; median nerve: 4 points on the pulp of the thumb, over the 2 nd MCP joint, the pulp of index and middle fingers, respectively-maximum score: 8 ; posterior tibial nerve: 10 points, on the tip of each toe, over the 1st and 5th metatarsophalangeal joints, the instep, the lateral border and the heel-maximum score: 20. Further details of the testing methodology were reported in a separate paper. ${ }^{8}$

\section{IMPAIRMENT OF NERVE FUNCTION}

A patient was diagnosed as having impairment if there was a deterioration of more than 2 points in the VMT score of an individual nerve or, similarly, 2 points or more in the TST score of a sensory nerve compared to the previous result, or maximum result in case previous results were not available. A reported onset of the neural impairment of less than 6 months previously was recorded as recent; otherwise it was recorded as old. The motor and sensory scores were further divided into 4 functional categories. Most patients had more than 1 nerve affected but in this paper treatment results are illustrated using only data on 1 ulnar nerve per patient. The functional categories are shown in Table 1.

\section{TREATMENT}

Only patients with recent neural impairment (see above), and who had no other 
Table 1. Functional scoring system for the ulnar nerve

\begin{tabular}{lcc}
\hline & Sensory score & Motor score \\
\hline Anaesthetic/Paralysed & $0-2$ & $0-2$ \\
Bad & 3 & $3-4$ \\
Moderate & 4 & $5-7$ \\
Good & $5-6$ & $8-10$ \\
\hline
\end{tabular}

concurrent severe illness, such as untreated tuberculosis, were considered eligible for steroid treatment. They received 1 of the following corticosteroid regimens:

1. Dexamethason 6 milligrams (mg) once daily (od) starting dose, tapering approximately $0.5 \mathrm{mg}$ every 2 weeks, depending on the progress of the patient, thus giving a duration of treatment of about 6 months.

2. Prednisolone $30 \mathrm{mg}$ twice daily (bd) starting dose, tapering approximately $5 \mathrm{mg}$ every 2 weeks, depending on the progress of the patient, thus giving a duration of treatment of about 6 months.

3. Prednisolone $60 \mathrm{mg}$ od starting dose, tapering approximately $5 \mathrm{mg}$ every 2 weeks, depending on the progress of the patient, thus giving a duration of treatment of about 6 months.

4. Prednisolone $40 \mathrm{mg}$ od starting dose, tapering approximately $5 \mathrm{mg}$ every 2 weeks, depending on the progress of the patient, thus giving a duration of treatment of about 4 months.

\section{STATISTICAL METHODS}

Risk factors were examined using logistic regression and the results are expressed as odds ratios. An odds ratio may be interpreted as the increase in risk in patients who have the risk factor compared to those who do not. For example, an odds ratio of 1.9 for bacteriological index means that patients with a positive skin smear had almost twice the risk of developing silent neuropathy as those with a negative skin smear. The difference between 2 paired samples was tested using the Wilcoxon matched-pairs signed-ranks test. ${ }^{9}$ A $p$-value of less than $5 \%$ was used as the level of statistical significance. Incidence rates were calculated as the number of patients developing new nerve function impairment during the follow-up period divided by the cumulative person years at risk. Patients were censored from the denominator as soon as the first episode of SN had occurred. Patients lost to follow-up due to death, defaulting or transferral only contributed person years to the denominator for as long as they were still followed up. Prevalence and incidence were only calculated for the sub-group of new patients. The $95 \%$ confidence interval is given in parentheses, e.g. $4 \cdot 2(2 \cdot 1-8 \cdot 2)$ means that there is $95 \%$ chance that the ratio actually lies between the values $2 \cdot 1$ and $8 \cdot 2$. Analysis was done using Epi Info software, version 5.01 ${ }^{10}$ and SPSS for Windows, version 6.0.

\section{Results}

PATIENTS

We included 536 patients in the study - 396 were new patients and 140 were old patients who either registered at GPH prior to the study period or were treated elsewhere before 
being referred to GPH. The mean age for the new patients was 41 years (range 2-88) and for the old patients 39 years (range 8-72). Among the new patients $70 \%$ were male against $81 \%$ among the old patients. The average follow-up time for new patients at the start of data analysis was 21 months (range 1-49). There were 2 TT, 202 BT, 7 BB, 133 $\mathrm{BL}, 42 \mathrm{LL}$ and 10 pure neuritic (PN) new patients, against $38 \mathrm{BT}, 6 \mathrm{BB}, 40 \mathrm{BL}, 40 \mathrm{LL}$ and 6 PN 'old' or referred patients -71 patients were or had been on DDS monotherapy, 344 patients had been or were on the multidrug regimen recommended by the World Health Organisation (WHO MDT). ${ }^{11}$ The regimen for paucibacillary patients consists of daily dapsone $100 \mathrm{mg}$ and once-monthly rifampicin $600 \mathrm{mg}$ (dosages are for adult patients). For multibacillary patients clofazimine is added in a dose of $50 \mathrm{mg}$ daily and $300 \mathrm{mg}$ once a month. The duration of each regimen expressed in monthly doses is 6 months and 24 months, respectively (1 patient had taken a different type of MDT).

\section{PREVALENCE AND INCIDENCE RATES}

Table 2 shows the prevalence of $\mathrm{SN}$ at first examination and the incidence rates during follow-up amongst the new patients. On average $6.8 \%$ of new patients presented with $\mathrm{SN}$ of recent onset at the time of diagnosis. More $\mathrm{SN}$ was diagnosed at the start of treatment than during or after treatment. Overall 52/396 new patients (13\%) developed 1 or more episodes of SN.

The overall incidence rate of SN was $4 \cdot 1$ per 100 person years at risk (PYAR). The rate difference between Ridley-Jopling classification groups was not significant statistically, but the numbers in each group were only small.

Table 3 presents the incidence of SN episodes by time of onset. The majority of episodes diagnosed after registration occurred during the first year of treatment $(75 \%)$.

\section{CROSS-OVER REACTIONS}

The phenomenon of 'cross-over reactions' is shown in Table 4: 18 patients (12 BT and 6 $\mathrm{BL}$ ) had a reversal reaction episode followed by SN. The reverse occurred in 6 patients (4 BT, 1 BL, 1 LL). Cross-over between ENL and SN occurred in $7 \mathrm{LL}$ patients $(4 \times \mathrm{ENL} \rightarrow \mathrm{SN}, 3 \times \mathrm{SN} \rightarrow \mathrm{ENL})$.

Table 2. Prevalence and incidence rates of SN among 396 new patients of leprosy at GPH

\begin{tabular}{lccccc}
\hline & \multicolumn{2}{c}{ Prevalence at registration } & & \multicolumn{2}{c}{ Incidence rates } \\
\cline { 2 - 3 } \cline { 5 - 6 } Classification & Number & $\%(95 \% \mathrm{Cl})^{\mathrm{a}}$ & & Number & per $100 \mathrm{PYAR}^{\mathrm{b}}$ \\
\hline TT & $0 / 2$ & & & $0 / 2$ & \\
BT & $11 / 202$ & $5 \cdot 4(2 \cdot 3-8 \cdot 6)$ & & $13 / 183$ & $4 \cdot 0(2 \cdot 4-7 \cdot 0)$ \\
BB & $0 / 7$ & & & $0 / 4$ & \\
BL & $12 / 133$ & $9 \cdot 0(4 \cdot 2-14)$ & & $5 / 106$ & $3 \cdot 0(1 \cdot 3-7 \cdot 3)$ \\
LL & $2 / 42$ & $4 \cdot 8(0-11)$ & & $4 / 31$ & $9 \cdot 1(3 \cdot 4-24)$ \\
PN & $2 / 10$ & $20(0-45)$ & & $1 / 10$ & $6 \cdot 7(0 \cdot 94-47)$ \\
Total & $27 / 396$ & $6 \cdot 8(4 \cdot 3-9 \cdot 3)$ & & $23 / 336$ & $4 \cdot 1(2 \cdot 7-6 \cdot 2)$ \\
\cline { 5 - 6 } & & & & \\
\hline
\end{tabular}

\footnotetext{
a $95 \%$ confidence interval, ${ }^{b}$ incidence expressed as the number of episodes of $\mathrm{SN}$ per 100 person years at risk (PYAR).
} 
Table 3. Occurrence of silent neuropathy episodes by time of onset among 396 new patients at GPH

\begin{tabular}{|c|c|c|c|c|c|c|c|c|}
\hline \multirow[b]{2}{*}{ Period } & \multicolumn{2}{|c|}{ BT } & \multicolumn{2}{|c|}{$\mathrm{BL}$} & \multicolumn{2}{|c|}{ LL } & \multicolumn{2}{|c|}{ PN } \\
\hline & Number & $\%$ & Number & $\%$ & Number & $\%$ & Number & $\%$ \\
\hline At registration & 12 & 46 & 13 & 72 & 2 & 33 & 1 & 50 \\
\hline $0-6$ months & 5 & 19 & 1 & $5 \cdot 6$ & 3 & 50 & & \\
\hline $7-12$ months & 5 & 19 & 3 & 16 & & & 1 & 50 \\
\hline 2nd year & 3 & 12 & 1 & 5 & 1 & 17 & & \\
\hline 3rd year & 1 & 4 & 0 & 5 & & & & \\
\hline Total & 26 & & 18 & & 6 & & 2 & \\
\hline
\end{tabular}

\section{TREATMENT}

Table 5 shows the progress of nerve functional scores during treatment. The median value of the sensibility score improved from 0 to $2 \cdot 5(z=-2 \cdot 65, p=0.008)$ over a period of 3 months, while the median value of the motor score improved from 6 to $7(z=2 \cdot 53$, $p=0 \cdot 012$ ) over the same period.

\section{RISK FACTORS}

The only risk factor of statistical significance was the extent of clinical disease expressed as the number of body areas involved in the disease, ${ }^{7}$ the number of enlarged nerves or the bacteriological index. If a cut-off point of 3 or more body areas (out of 9 ) was chosen to define 'extensive disease', the risk of SN was 3 times higher for patients with extensive disease compared to those with limited (=less than 3 body areas involved) disease (adjusted odds ratio $2 \cdot 8(1 \cdot 3-6 \cdot 0), p=0 \cdot 01)$. The risk factors are summarized in Table 6 .

\section{Discussion}

\section{AETIOLOGY AND TERMINOLOGY}

SN has been described as a separate clinical entity by several investigators. ${ }^{1-3}$ As far as we are aware the aetiologies of $\mathrm{SN}$ have not yet been conclusively investigated histopathologically. Some characteristics suggest that 'silent neuropathy of recent

Table 4. Cross-over reactions among 536 patients registered at GPH

\begin{tabular}{lrllr}
\hline & \multicolumn{4}{c}{ Classification } \\
\cline { 2 - 5 } Type of cross-over reaction & BT & BL & LL & Total \\
\hline $\mathrm{RR}^{\mathrm{a}} \rightarrow \mathrm{SN}^{\mathrm{b}}$ & 12 & 6 & & 18 \\
$\mathrm{SN} \rightarrow \mathrm{RR}$ & 4 & 1 & 1 & 6 \\
$\mathrm{ENL} \rightarrow \mathrm{SN}$ & & & 4 & 4 \\
$\mathrm{SN} \rightarrow \mathrm{ENL}$ & & & 3 & 3 \\
\hline
\end{tabular}

\footnotetext{
${ }^{\mathrm{a}} \mathrm{RR}$, reversal reaction; ${ }^{\mathrm{b}} \mathrm{SN}$, silent neuropathy; ${ }^{\mathrm{c}} \mathrm{ENL}$, erythema nodosum leprosum.
} 
Table 5. Progress of nerve function scores during and after steroid treatment in patients with $\mathrm{SN}$ of the ulnar nerve

\begin{tabular}{|c|c|c|c|c|}
\hline & $\begin{array}{l}\text { Start of } \\
\text { treatment }\end{array}$ & $\begin{array}{c}1 \\
\text { month }^{\mathrm{a}}\end{array}$ & $\begin{array}{c}3 \\
\text { months }^{\mathrm{a}}\end{array}$ & $\begin{array}{c}6 \\
\text { months }^{a}\end{array}$ \\
\hline \multicolumn{5}{|l|}{ Sensory function (ST) } \\
\hline Anaesthetic & $17(94)^{b}$ & $13(76)$ & $9(50)$ & $5(42)$ \\
\hline Bad & & & $1(6)$ & \\
\hline Moderate & $1(6)$ & $3(18)$ & $2(11)$ & $1(8)$ \\
\hline Good & & $1(6)$ & $6(33)$ & $6(50)$ \\
\hline Total & $18(100)$ & $17(100)$ & $18(100)$ & $12(100)$ \\
\hline Median of TST score (scale $0-6$ ) & 0 & & $2 \cdot 5$ & 5 \\
\hline \multicolumn{5}{|l|}{ Motor function (VMT) } \\
\hline Paralysed & $5(19)$ & $2(8)$ & $3(145)$ & $1(7)$ \\
\hline Bad & $3(12)$ & $2(8)$ & $1(4)$ & \\
\hline Moderate & $18(69)$ & $16(67)$ & $9(41)$ & $6(40)$ \\
\hline Good & & $4(17)$ & $9(41)$ & $8(53)$ \\
\hline Total & $26(100)$ & $24(100)$ & $22(100)$ & $15(100)$ \\
\hline Median of VMT score (scale $0-10$ ) & 6 & & 7 & 8 \\
\hline
\end{tabular}

\footnotetext{
${ }^{a}$ The intervals refer to the time between the start of the steroid treatment and the date of the nerve function assessment, ${ }^{b}$ number of patients; the numbers in parentheses are column percentages.
}

onset' is not necessarily the same as a reversal reaction in the nerve and, therefore, there may be several causes of SN.

First, the incidence rate of reversal reaction in borderline lepromatous patients was much higher than in lepromatous patients, ${ }^{12}$ while the incidence rate of $\mathrm{SN}$ was higher in lepromatous patients (rate ratio 3.0 (0.81-11.2)). Secondly, 'cross-over reactions' occurred between reversal reaction and $\mathrm{SN}$, as well as between ENL and SN. It would be conceivable that in some patients reversal reactions would only be manifest in the nerves, e.g. because skin lesions have 'burned out' during treatment. The latter could explain why some patients may have a reversal reaction at the beginning of their treatment, followed later by SN. But although this latter pattern is more common (Table 4), several patients first had SN followed by a reversal reaction with skin reaction. It is also difficult to believe that BL and LL patients would have more antigen in their nerves

Table 6. Risk factors for SN among 536 patients in GPH

\begin{tabular}{llc}
\hline Risk factor & Odds ratio & $p$-value \\
\hline Extent of clinical disease: & & \\
$>10$ skin lesions & $1 \cdot 2(0 \cdot 67-2 \cdot 0)^{\mathrm{a}}$ & $0 \cdot 60$ \\
$>3$ nerves enlarged & $3 \cdot 0(1 \cdot 4-6 \cdot 3)^{\mathrm{a}}$ & $0 \cdot 004$ \\
$\quad>2$ body areas involved & $2 \cdot 8(1 \cdot 3-6 \cdot 0)^{\mathrm{a}}$ & $0 \cdot 010$ \\
Bacteriological index & $1 \cdot 9(1 \cdot 1-3 \cdot 1)^{\mathrm{b}}$ & $0 \cdot 015$ \\
\hline
\end{tabular}

\footnotetext{
${ }^{a}$ Odds ratio adjusted for age, sex and bacteriological index, $\mathrm{b}$ adjusted for age, sex and extent of clinical disease.
} 
than in their skin, causing a neural rather than a skin reaction. The 'burned out lesion option' is unlikely because the majority of SN episodes were diagnosed at the beginning of treatment or during the first year (Table 3). If $\mathrm{SN}$ were just an expression of reversal reaction (RR) it remains difficult to explain why RRs sometimes occur in the skin, sometimes in skin and nerves and sometimes in the nerves only. The nature of SN can only be investigated (immuno-)histologically on nerve biopsies and by study of immunological markers during episodes of such neuropathy.

It has been shown that peripheral nerves of leprosy patients, particularly those of the lepromatous type, may already be affected subclinically at an early stage in the disease process. ${ }^{13-15}$ Schwann cell pathology, particularly in unmyelinated fibres, is one of the first pathophysiological processes to occur in leprous neuropathy. ${ }^{16-18}$ In addition, it is said that fibrosis following inflammation of the nerve tissue can be a further cause of neural impairment. ${ }^{15}$ Many investigators have reported a marked intraneural increase in fibrous tissue in leprosy. ${ }^{14,15,19-21}$ In advanced patients $\mathrm{Job}^{14}$ found that nerve tissue was sometimes completely replaced by collagen, leaving the nerve as a nonfunctional fibrous cord. Charosky et al.'s ${ }^{15}$ proposition that epineurial fibrosis leads to increased intraneural pressure and, thus, through ischemia to further 'neurological deficit', seems plausible. Despite this, there is no direct evidence that fibrosis actually leads to further nerve damage. Both these postulated early and late causes of functional impairment are strictly speaking not neuritis, i.e. inflammation of the nerve. We propose therefore to name the clinical phenomenon of silent impairment of nerve function with the descriptive term 'silent neuropathy' rather than to use the term 'silent neuritis'.

Besides Schwann cell degeneration and intraneural fibrosis there are at least 2 immunological processes that may cause SN. The first one is a cell-mediated immune reaction probably involving cytoplasmic antigens of Mycobacterium leprae. Although the immunological mechanism may be the same, lymphocytes from patients with a 'skin reaction' respond to different antigens (surface antigens) than those with a 'nerve reaction' (cytoplasmic antigens). ${ }^{5}$ Because this neural reaction is a cell-mediated immune process, it has been classified by some investigators as a 'reversal reaction in the nerves'. ${ }^{22}$ The second immunological reaction would be intraneural ENL. The occurrence of ENL lesions in peripheral nerves during an ENL reaction has been described by Pearson \& Ross. ${ }^{23}$ Whether this also occurs during episodes of SN has to our knowledge not been reported. As ENL lesions are usually tender, it seems unlikely that intraneural ENL would produce silent neuritis.

\section{TREATMENT}

In the clinical setting it will often not be clear which pathological process is causing a given episode of silent neural impairment and, indeed, it may well be that one or more of the suggested processes occur simultaneously and contribute together to the observed impairment. For the leprosy worker the difference is not so important, providing that he or she is actively looking for $\mathrm{SN}$, because neural impairment in both types of reaction responds to treatment with corticosteroids.

With a prevalence of $6 \cdot 8 \%$ and an incidence rate of $4 \cdot 1 / 100$ PYAR, SN was a common phenomenon among our patients. We found that during a $\mathrm{SN}$ episode in BL/LL the patients' neural impairment sometimes responded well to treatment with 
thalidomide only (unpublished observation). The SN patients who were treated with steroids showed good improvement in both sensory and motor function. The finding by Srinivasan et al. ${ }^{1}$ that the extent of neural impairment has a prognostic value for the outcome of treatment, was confirmed by our data. Nerves with complete loss of function or which were classified 'bad' were much less likely to recover to 'good' function, than those whose function was still 'moderate' at the beginning of treatment (data not shown).

\section{RISK FACTORS}

The extent of clinical disease as expressed by a count of the number of body areas involved in the disease, the number of enlarged nerves or the bacteriological index of the initial skin smear, was the only factor associated with a significantly increased risk of SN. This was not surprising as we have shown in a previous study that 'extensive disease' was a risk factor for any type of neural impairment. The suggestion by Parkhe et al. ${ }^{4}$ that treatment with MDT (as compared to DDS treatment) would give an increased risk of silent neuritis was not confirmed by our data.

\section{ASSESSMENT OF NEURAL FUNCTION}

Since regular assessment of neural function plays such a crucial role in the detection of silent neuropathy, the most sensitive methods that are operationally feasible should be employed. Recently, we have reported good results in the monitoring of sensibility of the hand and foot using Semmes-Weinstein monofilaments and moving 2-point discrimination. ${ }^{24}$ We believe that such instruments should be made widely available and that training should be given in their appropriate use to all health workers involved in the treatment of leprosy patients. If standardized filaments are not available, they can be made from locally available materials such a suture or fishing nylon, but straight nylon is to be preferred. ${ }^{25-27}$ Until the use of monofilaments has been implemented, the 'ballpen test' probably remains the best alternative.

\section{Conclusions}

$\mathrm{SN}$ is a common complication in Nepali leprosy patients.

Some epidemiological evidence suggests that $\mathrm{SN}$ is not equivalent to a ' $\mathrm{R} R$ expressing itself in the nerves'. Further (histopathological) investigation is needed.

Patients with more extensive clinical disease were at increased risk of developing SN. These patients should have their nerve function assessed at every clinic visit at least during their first year of treatment.

Regular nerve function assessment, using the most sensitive tests available, is essential to detect $\mathrm{SN}$ at an early stage and to prevent permanent nerve function impairment.

\section{Acknowledgments}

We are indebted to Dr D. D. Palande, Dr V. M. Inchley, Professor F. G. I. Jennekens and Dr Y. van der Graaf for their very helpful comments on this manuscript. We are 
grateful to the staff of the Physiotherapy Department at GPH who spent much of their time performing detailed nerve function assessments, without which this study would not have been possible. The work at GPH is dedicated to the service and glory of God.

\section{References}

${ }^{1}$ Srinivasan H, Rao KS, Shanmugam N. Steroid therapy in recent 'quiet nerve paralysis' in leprosy. Lepr Ind, 1982; 54: 412-9.

2 Duncan ME, Pearson JMH. Neuritis in pregnancy and lactation. Int J Lepr, 1982; 50: 31-8.

3 Hamilton J. Deformity prevention in the field: a systematic approach. Lepr Rev, 1983; 54: 229-37.

4 Parkhe SM, Smith WCS, Samson PD, Solomon M. Sudden paralysis associated with multi-drug therapy-a cautionary tale. Quad Coop San, 9: 380 (abstracts of the 13th International Leprosy Congress '88).

5 Barnetson RStC, Bjune G, Pearson JMH, Kronvall G. Cell mediated and humoral immunity in 'reversal reactions'. Int J Lepr, 1976; 44: 267-74.

6 Becx-Bleumink M, Berhe D, 'T Mannetje W. The management of nerve damage in the leprosy control services. Lepr Rev, 1990; 61: 1-11.

7 van Brakel WH, de Soldenhoff R, McDougall AC. The allocation of leprosy patients into paucibacillary and multibacillary groups for multidrug therapy, taking into account the number of body areas affected by skin, or skin and nerve lesions. Lepr Rev, 1992; 63: 231-45.

8 van Brakel WH, Khawas IB. Nerve damage in leprosy: an epidemiological study of 396 patients in West Nepal - part 1: definitions, methods and frequencies. Lepr Rev, 1994; 65: 204-21.

9 Armitage P, Berry G. Statistical methods in medical research. Second edition. Blackwell Scientific Publications, Oxford, 1987; p. 410.

10 Dean AG, Dean JA, Dicker RC. Epi Info, Version 5: a word processing, database, and statistics program for epidemiology on microcomputers, USD, Inc., Stone Mountain, Georgia, 1990.

11 WHO Expert Committee on leprosy, sixth Report. WHO Technical Report series. No. 768. WHO, Geneva, 1988.

12 van Brakel WH, Khawas IB. Reactions in leprosy: an epidemiological study of 386 patients in west Nepal. Lepr Rev, 1994; 65: 190-203.

13 Antia NH, Mehta LN, Shetty VP, Irani PF. Clinical, electrophysiological, quantitative, histologic and ultrastructural studies of the index branch of the radial cutaneous nerve in leprosy. I. Preliminary report. Int $J$ Lepr, 1975; 43: 106-13.

14 Job CK. Nerve damage in leprosy. Int J Lepr, 1989; 57: 532-9.

15 Charosky CB, Gatti JC, Cardama JE. Neuropathies in Hansen's disease. Int J Lepr, 1983; 51: 576-86.

16 Antia NH, Shetty VP, Mehta LN. Study of the evolution of nerve damage in leprosy: part IV-an assessment. Lepr Ind, 1980; 52: 48-52.

17 Tzourio C, Said G, Millan J. Asymptomatic nerve hypertrophy in lepromatous leprosy: a clinical, electrophysiological and morphological study. J Neurol, 1992; 239: 367-74.

18 Shetty VP, Antia NH, Jacobs JM. The pathology of early leprous neuropathy. J Neurol Sci, 1988; 88: 115-31.

19 Job CK. Mycobacterium leprae in nerve lesions in lepromatous leprosy. Arch Path, 1970; 89: 195-207.

20 Dastur DK. Pathology and pathogenesis of predilective sites of nerve damage in leprous neuritis. Nerves in the arm and the face. Neurosurg Rev, 1983; 6: 139-52.

21 Junqueira LCU, Montes GS, Neto EA, Barros C, Tedesco-Marchese AJ. The collagen of permanently damaged nerves in human leprosy. Int J Lepr, 1980; 48: 291-7.

22 Rose P, Waters MFR. Reversal Reactions in leprosy and their management. Lepr Rev, 1991; 62: 113-21.

23 Pearson JMH, Ross WF. Nerve involvement in leprosy-pathology, differential diagnosis and principles of management. Lepr Rev, 1975; 46: 199-212.

24 van Brakel WH, Shute J, Dixon JA, Arzet H. Evaluation of sensibility in leprosy-comparison of various clinical methods. Lepr Rev, 1994; 65: 106-21.

25 Naafs B, Dagne T. Sensory testing: a sensitive method in the follow-up of nerve involvement. Int J Lepr, 1977; 45: 364-8.

26 Palande DD, Bowden REM. Early detection of damage to nerves in leprosy. Lepr Rev, 1992; 63: 60-72.

27 Brandsma JW. Examination of touch/pressure perception with nylon filaments. In: The intrinsic minus hand. PhD thesis, University of Utrecht, 1993. 